\title{
ANALISIS FREKUENSI DATA SEISMIK HASIL MIGRASI FINITE DIFFERENCE
}

\author{
Jamaluddin ${ }^{1}$, Johanes Gedo Sea ${ }^{2}$, Yusuf Surachman Djajadihardja ${ }^{3}$, Muhammad Altin Massinai ${ }^{4}$, \\ Sabrianto Aswad ${ }^{4}$, Maria ${ }^{4}$ \\ ${ }^{1}$ Program Studi Teknik Geologi, STT-Migas Balikpapan \\ ${ }^{2}$ School of Geophysics and Information Technology, China University of Geosciences, Beijing \\ ${ }^{3}$ Badan Pengkajian dan Penerapan Teknologi (BPPT), Jakarta \\ ${ }^{4}$ Departemen Geofisika, Universitas Hasanuddin, Makassar \\ e-mail : jamaluddin@sttmigas.ac.id
}

\begin{abstract}
Abstrak. Migrasi beda hingga adalah salah satu algoritma migrasi yang menggunakan prinsip downward continuation dan gelombang datang yang diselesaikan secara numerik dengan menggunakan beda hingga. Migrasi dalam perangkat lunak ProMAX ini memiliki berbagai algoritma tergantung pada solusi numerik yang digunakan. Dari setiap algoritma migrasi beda hingga ini menunjukkan perbedaan signifikan dalam frekuensi yang dihasilkan. Migrasi dengan algoritma beda hingga eksplisit menunjukkan hasil frekuensi yang lebih baik daripada algoritma beda hingga implisit.
\end{abstract}

Kata Kunci: eksplisit; beda hingga; frekuensi; implisit; migrasi.

\begin{abstract}
Finite difference migration is one of the migration algorithms that uses the principle of downward continuation and upcoming waves which are solved numerically with finite difference. This migration in ProMAX software has various algorithms depending on the numerical solution used. From each finite difference migration algorithm this shows a significant difference in the frequency produced. Migration with the explicit finite difference algorithm shows better frequency results than the Implicit Finite Difference algorithm.
\end{abstract}

Keywords: explicit; finite difference; frequency; implicit; migration

\section{PENDAHULUAN}

Pengolahan data seismik dengan struktur geologi yang kompleks merupakan tantangan besar bagi tim pengolah data seismik untuk menghasilkan penampang seismik. Kompleksitas struktur yang disertai oleh perubahan kecepatan secara lateral bisa disebabkan oleh perubahan ketebalan atau perubahan fasies. Berbagai parameter matematis dikembangkan untuk memperoleh penampang seismik pada proses migrasi sebagai tahap akhir dari pengolahan data seismik.

Migrasi merupakan tahapan akhir dalam pengolahan data seismik yang bertujuan untuk mengembalikan reflektor miring ke posisi sebenarnya dan untuk menghilangkan efek dif raksi sehingga akan meningkatkan resolusi spasial dan menghasilkan gambaran seismik bawah permukaan (Yilmaz, 2001). Kebanyakan perkembangan metode migrasi ditujukan pada solusi persamaan gelombang seperti F-K migrasi, migrasi phase-shift, migrasi Kirchhoff, migrasi split-step fourier, dan migrasi finite difference. Finite Difference merupakan salah satu metode migrasi dalam pengolahan data seismik yang mencari operator diferensial pada persamaan gelombang baik secara eksplisit maupun implisit (Sea dkk., 2017).

Migrasi finite difference pertama kali diperkenalkan oleh (Claerbout, 1985; Claerbout dan Doherty, 1972) dimana beliau menggunakan persamaan gelombang secara langsung dalam proses pembuatan image dengan implementasi finite difference. Kemudian, Stoffa dkk. (1990) mengutip pendapat dari Baysal (1983) yang menyatakan bahwa pendekatan finite difference untuk persamaan gelombang membutuhkan pendekatan eksplisit dan implisit pada operator differensial persamaan gelombang. Sheriff dan Geldart (1995) mengembangkan pemikiran Claerbout (1985) dengan menerapkan metode finite difference untuk memperoleh solusi persamaan gelombang datang sehingga memperoleh diskrit posisi reflektor dalam pemodelan numerik. Liu dkk., (2009) serta Liu dan Sen (2009) mengembangkan pemikiran Claerbout dengan memberikan solusi persamaan gelombang dengan pendekatan implisit dan eksplisit finite difference hingga orde yang lebih tinggi sehingga variasi kecepatan vertikal dan lateral dapat terpenuhi. 
Pada penelitian ini akan dipaparkan hasil frekuensi dari beberapa algoritma migrasi finite difference serta membandingkan algoritma migrasi yang dapat mempertahankan frekuensi target dengan presisi.

\section{Teori Dasar Migrasi Finite Difference}

Migrasi finite difference merupakan metode migrasi yang menggunakan prinsip downward continuation. Permasalahan migrasi terkait dengan pemecahan persamaan gelombang skalar (Sheriff dan Geldart, 1995).

$$
\frac{\partial^{2} \Psi}{\partial x^{2}}+\frac{\partial^{2} \Psi}{\partial z^{2}}-\frac{1}{v^{2}} \frac{\partial^{2} \Psi}{\partial t^{2}}=0
$$

Pada prinsipnya metode finite difference terkait dengan transformasi koordinat penjalaran gelombang dibawah permukaan bumi. Transformasi koordinat dapat digunakan untuk mengamati penjalaran gelombang seismik pada arah tertentu. Jika suatu gelombang bidang mendekati permukaan dengan sudut $\theta$, maka solusi Persamaan (1) dapat di tulis.

$$
\Psi(x, z, t)=A \exp \left[j \omega\left\{t-\left(\frac{x}{v}\right) \sin \sin \theta-\left(\frac{z}{v}\right) \cos \cos \theta\right\}\right]
$$

Jika sudut gelombang sangat kecil, dimana $\sin \sin \theta=\theta$ dan $\cos \cos \theta=1-\frac{1}{2} \theta^{2}$, maka Persamaan (2) dapat dituliskan dalam bentuk:

$$
\Psi(x, z, t)=A \exp \left[j \omega\left\{t-\frac{x \theta}{v}-\frac{z}{v}+\frac{z \theta^{2}}{2 v}\right\}\right]
$$

Dengan mendefinisikan skala koordinat baru $t^{*}=t-\frac{z}{v}$ yang merupakan sistem koordinat gelombang yang berpropagasi ke receiver atau upcoming wave, Persamaan (3) dapat ditulis dengan bentuk:

$$
\psi^{*}\left(x, z, t^{*}\right)=A \exp \left[j \omega\left\{t^{*}-\frac{x \theta}{v}+\frac{z \theta^{2}}{2 v}\right\}\right]
$$

Transformasi persamaan gelombangnya adalah:

$$
\begin{aligned}
& \frac{\partial \Psi}{\partial t}=\frac{\partial \Psi^{*}}{\partial t^{*}} \frac{\partial t^{*}}{\partial t}=\frac{\partial \Psi^{*}}{\partial t^{*}} ; \frac{\partial^{2} \Psi}{\partial t^{2}}=\frac{\partial^{2} \Psi^{*}}{\partial t^{* 2}} \\
& \frac{\partial \Psi}{\partial x}=\frac{\partial \Psi^{*}}{\partial x} ; \frac{\partial^{2} \Psi}{\partial x^{2}}=\frac{\partial^{2} \Psi^{*}}{\partial x^{2}} \\
& \frac{\partial \Psi}{\partial z}=\frac{\partial \Psi^{*}}{\partial z}+\frac{\partial \Psi^{*}}{\partial t^{*}} \frac{\partial t^{*}}{\partial z}=\frac{\partial \Psi^{*}}{\partial z}-\frac{1}{v} \frac{\partial \Psi^{*}}{\partial t^{*}} \\
& \frac{\partial^{2} \Psi}{\partial z^{2}}=\frac{\partial^{2} \Psi^{*}}{\partial z^{2}}-\frac{2}{v} \frac{\partial^{2} \Psi^{*}}{\partial z \partial t^{*}}+\frac{1}{v^{2}} \frac{\partial^{2} \Psi^{*}}{\partial t^{* 2}}
\end{aligned}
$$

Berdasarkan transformasi tersebut maka diperoleh persamaan gelombang upcoming berupa:

$$
\frac{\partial^{2} \psi^{*}}{\partial x^{2}}+\frac{\partial^{2} \psi^{*}}{\partial z^{2}}-\frac{2}{v} \frac{\partial^{2} \psi^{*}}{\partial z \partial t^{*}}=0
$$

Dengan menggunakan aproksimasi $15^{\circ}$, dimana digunakan asumsi bahwa gelombang menjalar hampir vertikal, perubahan $\Psi^{*}$ terhadap $\mathrm{z}$ sangat kecil, sehingga untuk sistem koordinat seperti ini dapat dituliskan persamaan aproksimasi $15^{\circ}$ dalam bentuk:

$$
\frac{\partial^{2} \psi^{*}}{\partial x^{2}}-\frac{2}{v} \frac{\partial^{2} \Psi^{*}}{\partial z \partial t^{*}}=0
$$

Untuk menyelesaikan persamaan (7) diatas maka dapat digunakan pendekatan diskrit finite difference

$$
\begin{gathered}
\frac{\partial^{2} \Psi^{*}}{\partial \mathrm{x}^{2}} \approx \frac{\Psi^{*}\left(\mathrm{x}, \mathrm{z}, \mathrm{t}^{*}\right)-2 \Psi^{*}\left(\mathrm{x}-\Delta \mathrm{x}, \mathrm{z}, \mathrm{t}^{*}\right)}{(\Delta \mathrm{x})^{2}}+\frac{\Psi^{*}\left(\mathrm{x}-2 \Delta \mathrm{x}, \mathrm{z}, \mathrm{t}^{*}\right)}{(\Delta \mathrm{x})^{2}} \\
\frac{\partial^{2} \Psi^{*}}{\partial \mathrm{z} \partial \mathrm{t}^{*}} \approx \frac{\Psi^{*}\left(\mathrm{x}, \mathrm{z}, \mathrm{t}^{*}\right)}{\Delta \mathrm{z} \Delta \mathrm{t}^{*}}-\frac{\Psi^{*}\left(\mathrm{x}, \mathrm{z}-\Delta \mathrm{z}, \mathrm{t}^{*}\right)}{\Delta \mathrm{z} \Delta \mathrm{t}^{*}}-\frac{\Psi^{*}\left(\mathrm{x}, \mathrm{z}, \mathrm{t}^{*}-\Delta \mathrm{t}^{*}\right)}{\Delta \mathrm{z} \Delta \mathrm{t}^{*}}+ \\
\frac{\Psi^{*}\left(\mathrm{x}, \mathrm{z}-\Delta \mathrm{z}, \mathrm{t}^{*}-\Delta \mathrm{t}^{*}\right)}{\Delta \mathrm{z} \Delta \mathrm{t}^{*}}
\end{gathered}
$$

\section{METODOLOGI}

Data yang digunakan merupakan data sekunder milik BPPT serta Software yang digunakan dalam penelitian ini adalah ProMAX dengan lisensi milik BPPT. Tahap preprocessing ini meliputi proses analisa spektral, pemfilteran data menggunakan bandpass filter, penguatan amplitudo menggunakan Automatic Gain Control (AGC), True Amplitude Recovery, dan dekonvolusi. Analisa kecepatan dilakukan pada interval CDP 200 dengan total CDP adalah 32778.

Migrasi finite difference pertama yang dilakukan menggunakan modul Explicit FD Depth Migration. Migrasi ini menggunakan frekuensi maksimum hingga $120 \mathrm{~Hz}$. Input pada flow ini adalah hasil dari final stack dengan parameter kecepatan yang digunakan adalah kecepatan interval domain kedalaman. Parameter yang digunakan dalam flow (Gambar 1).

\begin{tabular}{|ll|}
\hline \multicolumn{2}{|c|}{ Dxplicit FD Depth Hig } \\
\hline CDP interval (feet or meters) & 6.25 \\
Maximum frequency (in Hz) & 120. \\
Depth sampl ing interval of output data & 0. \\
Maximum depth to migrate & 20000. \\
What maximum dip would you like to migrate to? & 50 degrees \\
Percent to pad trace length & 30. \\
Get interval velocities from database? & Yes No \\
Select interval vs. depth velocity file & velan2interval indepth \\
Change panel ing parameters? & Yes Ho \\
Change the default tapering? & Yes Ho \\
Re-apply trace mutes in dopth? & Yes No \\
Re-kill dead traces? & Yes No \\
\hline
\end{tabular}

Gambar 1. Parameter yang digunakan pada modul Explicit FD Depth Migration.

Migrasi finite difference yang kedua dilakukan dengan menggunakan modul Steep Dip Explicit FD Time Migration. Migrasi ini menggunakan frekuensi maksimum sampai dengan $80 \mathrm{~Hz}$ (Gambar 2). Kecenderungan data hasil migrasi hingga $120 \mathrm{~Hz}$, 
frekuensi dominan yang dihasilkan adalah hingga 80 $\mathrm{Hz}$ saja sehingga untuk migrasi selain Explicit $F D$ Depth Migration hanya menggunakan frekuensi hingga $80 \mathrm{~Hz}$. Input pada flow ini adalah hasil dari final stack dengan parameter kecepatan yang digunakan adalah kecepatan interval domain waktu.

Migrasi finite difference yang ketiga dilakukan dengan menggunakan modul Fast Explicit FD Time Migration (Gambar 3). Migrasi menggunakan frekuensi maksimum hingga $80 \mathrm{~Hz}$. Input pada flow ini adalah hasil dari final stack dengan parameter kecepatan yang digunakan adalah kecepatan interval domain waktu.

\begin{tabular}{|ll|}
\hline \multicolumn{2}{|c|}{ Steep Dip Explicit FD Time Mig. } \\
\hline CDP interval (feet or meters) & 6.25 \\
Haximun frequency (in Hz) & 80. \\
Haximun dip to migrate & 50 degrees \\
Percent to pad trace length & 30. \\
Cet interval velocities from database? & Yes No \\
Select interval vs. time velocity file & velan2 (Interval in Time) \\
Change panel ing parameters? & Yes $\mathrm{No}$ \\
Change the default tapering? & Yes $\mathrm{No}$ \\
Re-apply trace mutes? & Yes No \\
Re-kill dead traces? & Yes No \\
\hline
\end{tabular}

Gambar 2. Parameter yang digunakan pada modul Steep Dip Explicit FD Time Migration.

\begin{tabular}{|c|c|}
\hline \multicolumn{2}{|c|}{ Fast Explicit FD Time Hig. } \\
\hline CDP interval (feet or meters) & 6.25 \\
\hline Maximum frequency (in $\mathrm{Hz}$ ) & 80. \\
\hline Time step for migration diffraction ten & 0. \\
\hline Percent to pad trace length & 30. \\
\hline cet interval velocities from database? & $\begin{array}{l}\text { Yes No } \\
\text { velan2 (Interval in Time) }\end{array}$ \\
\hline $\begin{array}{l}\text { Select interval vs. time velocity file } \\
\text { change panel ing parameters? }\end{array}$ & $\begin{array}{l}\text { velan' (Interval in Time) } \\
\text { Yes } 110\end{array}$ \\
\hline Change the default tapering? & Yes llo \\
\hline Retain input sample rate? & Yes 110 \\
\hline Re-apply trace mutes? & Yes No \\
\hline Re-kill dead traces? & Yes No \\
\hline
\end{tabular}

Gambar 3. Parameter yang digunakan pada modul Fast Explicit FD Time Migration.

Migrasi finite difference yang keempat dilakukan dengan menggunakan modul Implicit $F D$ Depth Migration (Gambar 4). Migrasi ini menggunakan frekuensi maksimum hingga $80 \mathrm{~Hz}$ dengan kedalaman target migrasi hingga $20000 \mathrm{~m}$. Input pada flow ini adalah hasil dari final stack dengan parameter kecepatan yang digunakan adalah kecepatan interval domain kedalaman.

Migrasi finite difference yang kelima dilakukan dengan menggunakan modul Implicit FD Time Migration. Sama seperti Implicit FD Depth Migration, migrasi ini menggunakan frekuensi maksimum hingga $80 \mathrm{~Hz}$ dengan kedalaman target migrasi hingga $20000 \mathrm{~m}$ (Gambar 5). Input pada flow ini adalah hasil dari final stack dengan parameter kecepatan yang digunakan adalah kecepatan interval domain waktu.

\begin{tabular}{|c|c|}
\hline \multicolumn{2}{|l|}{ Implicit FD Depth Mig. } \\
\hline Minimum CDP to migrate & 1 \\
\hline Maximum CDP to migrate & 32778 \\
\hline CDP interval (ft or meters) & 6.25 \\
\hline Minimum frequency to migrate (in $\mathrm{Hz}$ ) & 10. \\
\hline Maximum frequency vs depth to migrate & $0-80,20000-80 /$ \\
\hline $\begin{array}{l}\text { Get interval vs depth velocities from DaTaBase? } \\
\text { SELECT Interval vs depth Velocity File }\end{array}$ & $\begin{array}{l}\text { Yes No } \\
\text { velan2 (interval in depth) }\end{array}$ \\
\hline Percent velocity scale factor & 100. \\
\hline$T$ ime attenuation factor $(\mathrm{dB} / \mathrm{sec})$ & 2. \\
\hline Migration step size (feet or meters) & 0. \\
\hline Maximum depth to migrate (feet or meters) & 20000 \\
\hline Defines the largest angle to properly migrate. & $\begin{array}{l}45 \\
\text { DEPTH }\end{array}$ \\
\hline $\begin{array}{l}\text { Output the migration in Depth or Time? } \\
\text { change the default tapering? }\end{array}$ & Yes no \\
\hline $\begin{array}{l}\text { Change the default tapering? } \\
\text { Re-kill dead traces? }\end{array}$ & Yes no \\
\hline
\end{tabular}

Gambar 4. Parameter yang digunakan pada modul Implicit FD Depth Migration.

\begin{tabular}{|ll|}
\hline \multicolumn{2}{|c|}{ Implicit FD Time Hig. } \\
\hline Hinimum CDP to migrate & 1 \\
Haximum CDP to migrate & 32778 \\
CDP interval (ft or meters) & 6.25 \\
Hinimum frequency to migrate (in Hz) & 10. \\
Haximum frequency vs depth to migrate & $0-80,20000-80 /$ \\
Cet interval velocities vs. time from DaraBasE? & Yes No \\
sELECr Interval vs time Velocity File & velan2 (Interval in Time) \\
Percent velocity scale factor & 100. \\
Time attenuation factor (dB/sec) & 2. \\
Higration step size (feet or meters) & 0. \\
Haximum depth to migrate (feet or meters) & 20000 \\
Defines the largest angle to properly migrate. & 45 \\
output the migration in Depth or Time? & TIME \\
Change the default tapering? & Yes Ho \\
Re-apply trace mutes? & Yes No \\
Re-kill dead traces ? & Yes No \\
\hline
\end{tabular}

Gambar 5. Parameter yang digunakan pada modul Implicit FD Time Miaration.

\section{HASIL DAN PEMBAHASAN}

Penampang seismik yang dihasilkan dari kelima migrasi ini memiliki karakteristik dan hasil yang berbeda-beda. Input parameter pada masingmasing modul migrasi tersebut sebagian besar sama seperti minimum dan maksimum CDP data, interval CDP yang telah didefinisikan pada geometri data, maksimum frekuensi yang digunakan untuk migrasi, dan model kecepatan yang digunakan.

Penampang seismik hasil final stack pada CDP 1 sampai dengan CDP 100 menunjukkan frekuensi data yang dominan pada rentang $10 \mathrm{~Hz}$ sampai dengan $90 \mathrm{~Hz}$ dan $105 \mathrm{~Hz}$ sampai dengan $115 \mathrm{~Hz}$ karena memiliki energi di atas $-20 \mathrm{~dB}$ Power. Data yang memiliki rentang frekuensi antara $95 \mathrm{~Hz}$ sampai dengan $105 \mathrm{~Hz}$ mengalami penurunan energi pada sebesar $-18 d B$ Power yang sebelumnya berada pada $-25 d B$ Power menjadi sekitar $-43 d B$ Power. Frekuensi tinggi di atas $120 \mathrm{~Hz}$ telah berada dibawah -60 dB Power karena telah berhasil di filter pada tahap pre-prosesing dan F-K Filter (Gambar 6). 


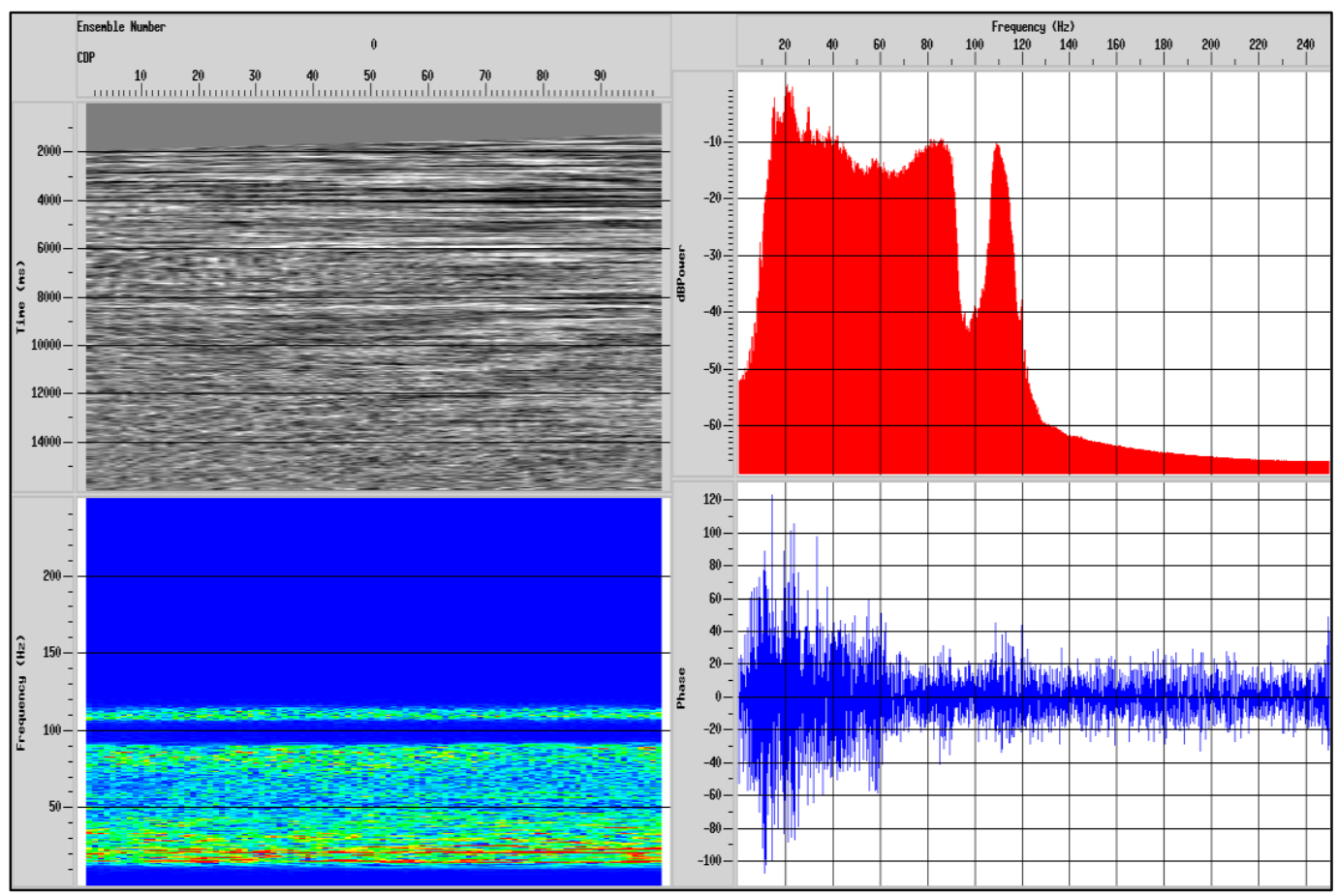

Gambar 6. Komponen frekuensi hasil dari final stack.

Berdasarkan Explicit FD Depth Migration pada CDP 1 sampai dengan CDP 100 menunjukkan frekuensi data yang dominan berada pada rentang 5 $\mathrm{Hz}$ sampai dengan $75 \mathrm{~Hz}$. Migrasi ini meningkatkan energi frekuensi rendah dan menurunkan energi frekuensi tinggi. Pada rentang frekuensi $5 \mathrm{~Hz}$ sampai dengan $10 \mathrm{~Hz}$ yang sebelum dimigrasi memiliki energi di bawah -20 $d B$ Power meningkat hingga diatas -20 $d B$ Power. Rentang frekuensi antara $105 \mathrm{~Hz}$ sampai dengan $115 \mathrm{~Hz}$ yang sebelumnya memiliki energi di atas $-20 d B$ Power menurun secara linear menjadi $-43 d B$ Power sampai dengan $-50 d B$ Power (Gambar 7).

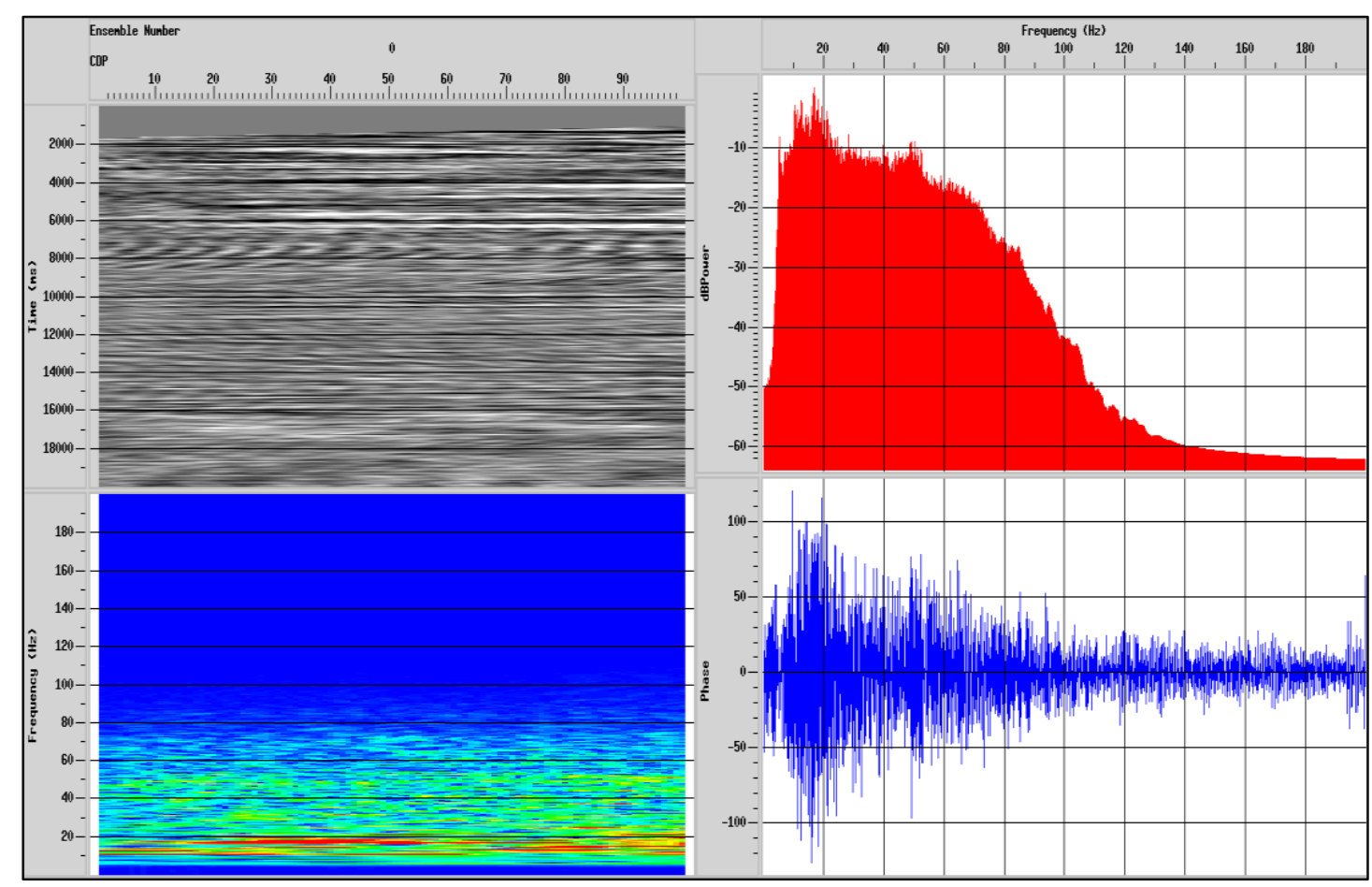

Gambar 7. Komponen frekuensi hasil dari Explicit FD Depth Migration. 


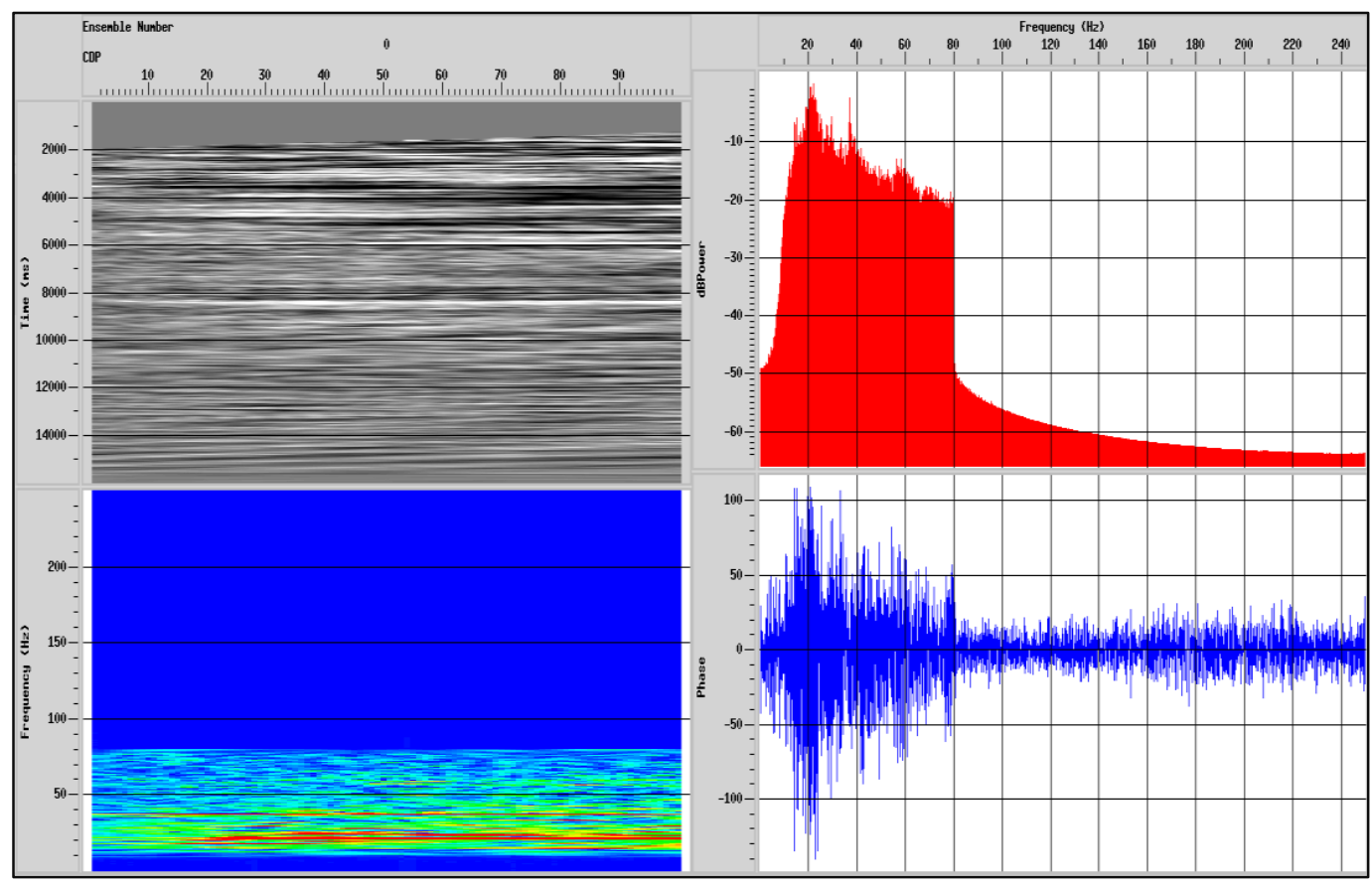

Gambar 8. Komponen frekuensi hasil dari Steep Dip Explicit FD Time Migration.

Data yang belum dimigrasi pada rentang frekuensi $100 \mathrm{~Hz}$ sampai dengan $110 \mathrm{~Hz}$ mengalami peningkatan energi sebesar $30 \mathrm{~dB}$ Power dari $-40 \mathrm{~dB}$ Power menjadi -10 $d B$ Power, namun setelah melalui tahap Explicit FD Depth Migration pada rentang frekuensi ini mengalami penurunan energi sekitar $8 d B$ Power dari -42 $d B$ Power menjadi -50 $d B$ Power. Frekuensi data hasil migrasi ini juga menunjukkan eliminasi pada frekuensi data seismik yang sebelumnya data berfrekuensi dominan hingga $120 \mathrm{~Hz}$ menjadi data berfrekuensi dominan hingga $75 \mathrm{~Hz}$, namun frekuensi data masih berada pada rentang $10 \mathrm{~Hz}$ sampai dengan $120 \mathrm{~Hz}$. Hasil migrasi ini juga masih memiliki frekuensi tinggi di atas $120 \mathrm{~Hz}$ tetapi memiliki energi yang rendah dibawah $-50 \quad d B$ Power sehingga tidak mempengaruhi penampang hasil migrasi.

Hasil dari Steep Dip Explicit FD Time Migration pada CDP 1 sampai dengan CDP 100 menunjukkan frekuensi data yang dominan berada pada rentang $10 \mathrm{~Hz}$ sampai dengan $80 \mathrm{~Hz}$. Dari hasil Explicit FD Depth Migration menunjukkan bahwa data yang dimigrasi hingga $120 \mathrm{~Hz}$ hanya memperlihatkan sinyal dengan frekuensi dominan hingga $80 \mathrm{~Hz}$ sehingga migrasi selanjutnya hanya menggunakan frekuensi maksimal $80 \mathrm{~Hz}$ (Gambar 8).
Migrasi ini menurunkan energi berfrekuensi rendah dan tinggi. Hasil final stack menunjukkan frekuensi $60 \mathrm{~Hz}$ sampai dengan $80 \mathrm{~Hz}$ berada di atas $17 d B$ Power, namun setelah melalui migrasi ini energinya berkurang dibawah $17 d B$ Power. Frekuensi data pada rentang $105 \mathrm{~Hz}$ sampai dengan $115 \mathrm{~Hz}$ awalnya berenergi diatas $-20 \mathrm{~dB}$ Power namun energinya berkurang drastis hingga di bawah $-50 d B$ Power setelah melalui migrasi ini. Migrasi ini menjaga data tetap aman dengan mereduksi noise yang berfrekuensi di bawah $10 \mathrm{~Hz}$ dan diatas 120 $\mathrm{Hz}$.

Hasil dari Fast Explicit FD Time Migration pada CDP 1 sampai dengan CDP 100 menunjukkan frekuensi data yang dominan berada pada rentang $12 \mathrm{~Hz}$ sampai dengan $80 \mathrm{~Hz}$ yang sebelumnya dominan berada pada rentang $10 \mathrm{~Hz}$ sampai dengan $120 \mathrm{~Hz}$. Migrasi ini meningkatkan energi frekuensi rendah dan mengurangi energi frekuensi tinggi. Rentang frekuensi antara $10 \mathrm{~Hz}$ sampai dengan $80 \mathrm{~Hz}$ konsisten memiliki frekuensi dengan energi diatas -20 $d B$ Power. Frekuensi rendah dibawah $10 \mathrm{~Hz}$ meningkat dari yang sebelum dimigrasi berada pada energi dibawah $-50 d B$ Power menjadi di atas $-50 \mathrm{~dB}$ Power. 
Peningkatan energi frekuensi rendah ini sedikit mempengaruhi bagian bawah penampang seismik hasil dari Fast Explicit FD Time Migration ini. Frekuensi tinggi pada rentang $105 \mathrm{~Hz}$ sampai dengan $115 \mathrm{~Hz}$ yang sebelumnya dimigrasi memiliki energi di atas -20 $d B$ Power telah berkurang energinya sehingga sinyal seismik bagian atas yang berada pada frekuensi ini tidak nampak secara signifikan. Noise yang berfrekuensi tinggi di atas $120 \mathrm{~Hz}$ konsisten memiliki energi dibawah $-50 \mathrm{~dB}$ Power baik sebelum dimigrasi maupun setelah melalui tahap migrasi ini (Gambar 9).

Hasil Implicit FD Depth Migration pada CDP 1 sampai dengan CDP 100 menunjukkan frekuensi data yang dominan adalah dari $4 \mathrm{~Hz}$ sampai dengan $37 \mathrm{~Hz}$. Migrasi ini meningkatkan energi frekuensi rendah dan mengurangi energi frekuensi tinggi. Frekuensi data pada final stack dominan pada rentang $10 \mathrm{~Hz}$ sampai dengan $90 \mathrm{~Hz}$ dan $105 \mathrm{~Hz}$ sampai dengan $115 \mathrm{~Hz}$ yang berada di atas $-20 \mathrm{~dB}$ Power menurun energinya setelah melalui migrasi ini (Gambar 10).

Pada data sebelum dimigrasi rentang frekuensi antara $40 \mathrm{~Hz}$ sampai dengan $95 \mathrm{~Hz}$ memiliki energi diatas -20 dB Power namun setelah melalui Implicit FD Depth Migrasi, frekuensi tersebut memiliki energi di bawah - $25 d B$ Power. Energi frekuensi yang ditargetkan mencapai $120 \mathrm{~Hz}$ menurun secara drastis energinya sehingga penampang sinyal bagian atas data yang berfrekuensi tinggi tidak nampak secara signifikan. Frekuensi noise di bawah $10 \mathrm{~Hz}$ yang awalnya berenergi di bawah $-50 \mathrm{~dB}$ Power meningkat energinya hingga $-25 d B$ Power sehingga noise berfrekuensi rendah ini mendominasi penampang seismik yang dihasilkan. Reflektor primer bagian atas penampang seismik yang berfrekuensi di atas $80 \mathrm{~Hz}$ kurang menampakkan sinyalnya karena energi frekuensi ini menurun hingga dibawah -20 $d B$ Power, demikian juga bagian bawah penampang seismik kurang menampakkan sinyal reflektor primernya karena dipengaruhi noise berfrekuensi rendah.

Hasil dari Implicit FD Time Migration pada CDP 1 sampai dengan CDP 100 menunjukkan frekuensi data yang dominan berada pada frekuensi $1 \mathrm{~Hz}$ sampai dengan $240 \mathrm{~Hz}$. Migrasi ini meningkatkan energi frekuensi yang tinggi dan rendah. Frekuensi data seismik yang berada di atas $-20 d B$ Power adalah pada rentang $1 \mathrm{~Hz}$ sampai dengan 60 $\mathrm{Hz}$. Frekuensi data yang awalnya dominan berada pada rentang $10 \mathrm{~Hz}$ sampai dengan $120 \mathrm{~Hz}$ setelah melalui proses migrasi ini dominan berada pada rentang $1 \mathrm{~Hz}$ sampai dengan $60 \mathrm{~Hz}$ (Gambar 11). Data yang belum di migrasi pada rentang frekuensi antara $60 \mathrm{~Hz}$ sampai dengan $90 \mathrm{~Hz}$ memiliki energi frekuensi diatas $-20 \mathrm{~dB}$ Power tetapi setelah melalui tahap Implicit FD Time Migration mengalami penurunan energi hingga dibawah $-20 \mathrm{~dB}$ Power.

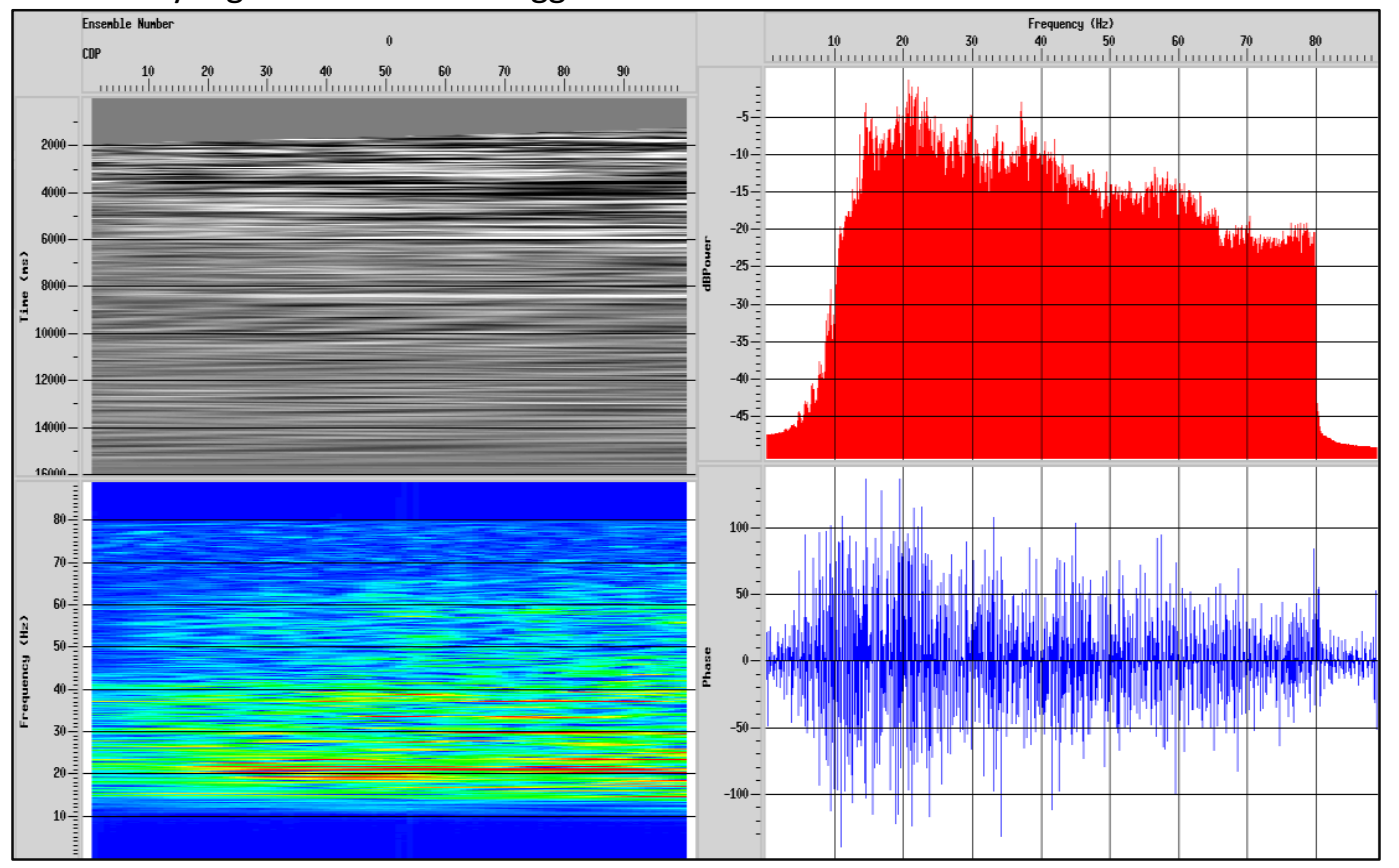

Gambar 9. Komponen frekuensi hasil dari Fast Explicit FD Time Migration. 


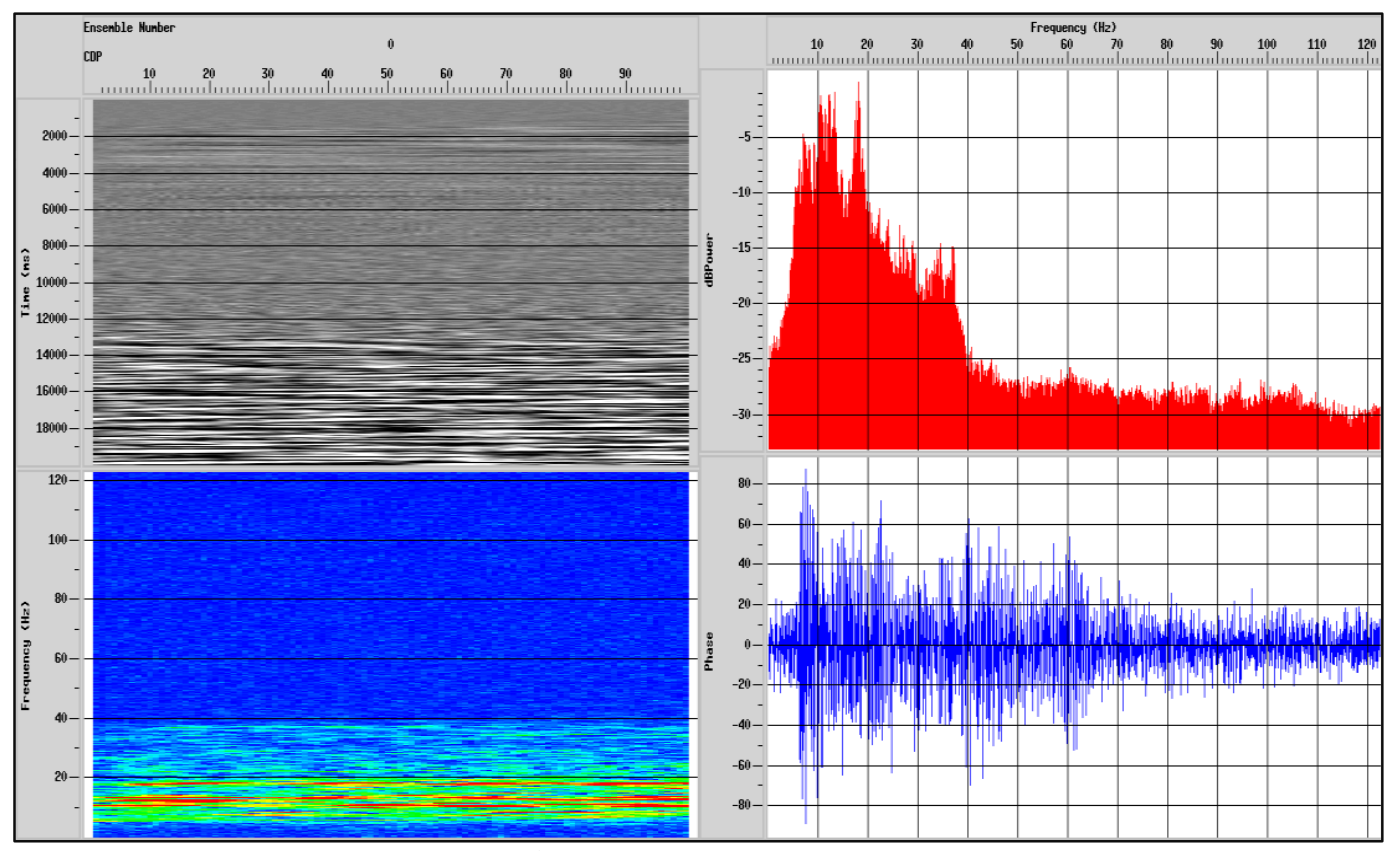

Gambar 10. Komponen frekuensi hasil dari Implicit FD Depth Migration.

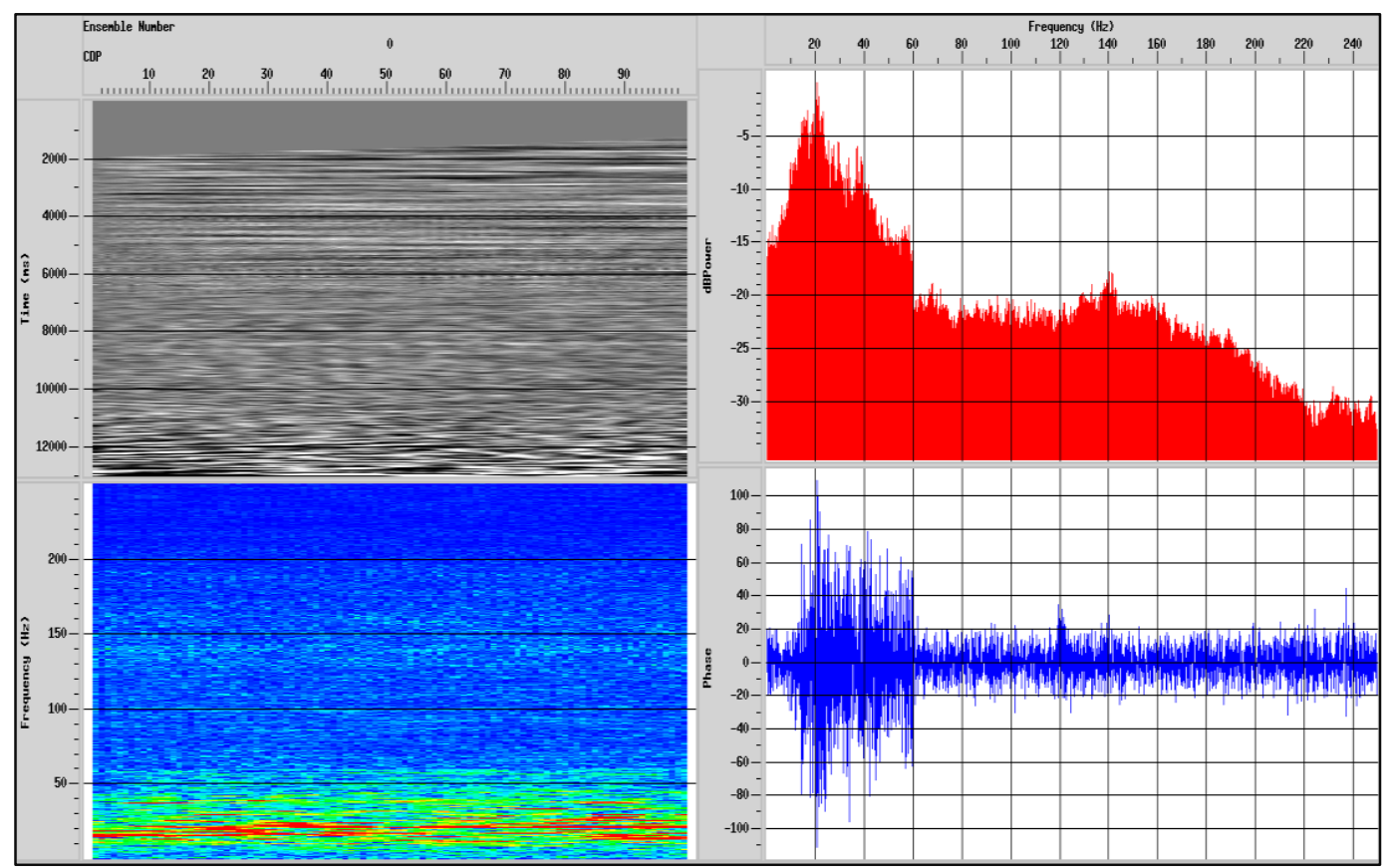

Gambar 11. Komponen frekuensi hasil dari Implicit FD Time Migration.

Frekuensi yang berada diatas $120 \mathrm{~Hz}$ awalnya berada di bawah $-50 d B$ Power meningkat hingga diatas - $25 d B$ Power. Frekuensi noise yang berada di atas $125 \mathrm{~Hz}$ ini muncul kembali dalam penampang seismik ini sehingga mengurangi energi frekuensi refleksi primer pada data.

\section{PENUTUP}

\section{Simpulan}

Dari kelima migrasi yang digunakan tersebut, migrasi finite difference dengan algoritma Explicit menunjukkan hasil frekuensi yang lebih baik dibandingkan dengan algoritma Implicit. Migrasi Explicit Finite Difference berhasil mempertahankan frekuensi data sesuai dengan target yang diinginkan dengan presisi.

\section{Saran}

Adapun saran untuk studi dan penelitian selanjutnya adalah agar mendapatkan hasil yang optimal untuk interpretasi, sebaiknya digunakan migrasi lain sebagai pembanding.

\section{Ucapan Terima Kasih}

Penulis menyampaikan ucapan terima kasih kepada pihak- yang telah membantu penelitian ini 
khususnya kepada Badan Pengkajian dan Penerapan Teknologi (BPPT).

\section{DAFTAR PUSTAKA}

Claerbout, J.F. (1985), Imaging the Earth's Interior, illustrated edition edition., Blackwell Science Inc, Oxford England ; Boston.

Claerbout, J.F. dan Doherty, S.M. (1972), "Downward continuation of moveout-corrected seismograms", GEOPHYSICS, Vol.37, No.5, hal. 741-768. http://doi.org/10.1190/1.1440298.

Liu, Y. dan Sen, M. (2009), "A practical implicit finitedifference method: Examples from seismic modelling", Journal of Geophysics and Engineering, Vol.6, hal. 231. http://doi.org/10.1088/1742-2132/6/3/003.

Liu, Y., Sen, M. dan Jackson, K. (2009), "Advanced finitedifference methods for seismic modeling", Geohorizons, Vol.14.

Sea, J.G., Massinai, M.A., Aswad, S. dan Djajadihardja, Y.S. (2017), Migrasi Data Seismik 2D Marine Menggunakan Pendekatan Finite Difference (Studi Kasus: Tenggara Pulau Simeulue), Diambil dari

http://repository.unhas.ac.id/handle/12345678 9/23621.

Sheriff, R.E. dan Geldart, L.P. (1995), Google-Books-ID: WRYgAwAAQBAJ, Exploration Seismology, Cambridge University Press.

Stoffa, P., Fokkema, J.T., FREIRE, R. dan Kessinger, W.P. (1990), "Split-Step Fourier Migration", Geophysics 55(4), 410-421. (1990), Vol.55. http://doi.org/10.1190/1.1442850.

Yilmaz, Ö. (2001), Seismic Data Analysis: Processing, Inversion, and Interpretation of Seismic Data, Society of Exploration Geophysicists. http://doi.org/10.1190/1.9781560801580. 